\title{
Una máquina teatral: Forma e identidad en el teatro de Migdalia Cruz
}

\author{
Analola Santana
}

Entrar en la máquina, salir de la máquina, estar en la máquina, bordearla, acercarse a ella, todo eso también forma parte de la máquina: son los estados del deseo, independientemente de cualquier interpretación.

- Gilles Deleuze y Félix Guattari

La obra de Migdalia Cruz, dramaturga de origen puertorriqueño que reside en Estados Unidos, sobresale no sólo por su estética, sino por los temas y personajes que desarrolla. Cruz se apodera de personajes pertenecientes a sectores calificados como grotescos y de bajo orden social y los "reinventa" al ofrecerles una voz poética, misma que les permite desarrollar convenciones de belleza a las que no pueden acceder o que les son negadas por la sociedad. Su estética trasciende cualquier intento de definición de una identidad latina en Estados Unidos, puesto que en ella existe una preocupación central por el espíritu humano y su sufrimiento. Obviamente en la obra de Cruz se puede reconocer una afinidad cultural con la experiencia latina en los Estados Unidos, pero esto se une al deseo de presentar imágenes que son disonantes respecto de los estereotipos que porta el público. La importancia de la obra teatral de Cruz reside en la manera en que desarrolla ciertos temas en su escritura que rompen los bordes del canon de la escritura latina. Su corpus teatral irrumpe con un grito de desesperación, terror y placer ante la condición humana.

El objetivo de este trabajo es estudiar la estética de Cruz en dos de sus obras, Fur (2000) y Miriam's Flowers (1992), a partir del análisis del tratamiento de dos temas, el amor y la sexualidad, y de la forma en que ambos estructuran a sus personajes, sobre todo los femeninos. De esta manera, se 
podrá identificar la forma en el que tratamiento semántico del cuerpo y los sentimientos amorosos distinguen el corpus de Cruz respecto de los ideales culturales tradicionales y crea una estética que da voz y humanidad a los más desposeídos. Es así como encuentra belleza en lo que se desprecia y recrea un concepto del teatro latino que acoge lo que antes se había rechazado.

\section{La creación de una identidad híbrida}

El teatro de Migdalia Cruz establece ciertos patrones que definen su obra. Ella crea un estilo teatral propio en el cual la convergencia de personajes de diversa índole tiene como efecto la subversión del estereotipo que el mainstream presenta de la identidad latina. Señala:

Many stereotypes have been written, and that's one of the reasons I write, because I feel like they've now been explored as people. From what you see on TV, the drug dealer's mother just says " $i A y$, mi madre!" and that's the character. I think the Puerto Rican or Colombian drug dealer's mother is probably a really interesting woman and must be going through an awful time, and that's what I like to write about. In writing about those things, I find hope. Unless you look at something, you can't define it. And until you define it, you can't fix it. (López 209)

Esta reinvención del estereotipo permite la creación de personajes cuyas acciones denotan una ruptura con los mandatos culturales dominantes. Son personajes que reflejan un choque entre culturas y realidades en el momento en que intentan definir una identidad para sí mismos. La manera en que éstos aparecen en el escenario pone de manifiesto el conflicto cultural en el cual se desarrollan la mayor parte de las diferentes culturas latinas en los Estados Unidos.

Alicia Arrizón toma prestado el término transculturación para definir la manera en que funciona el performance creado por la mujer latina. Dice al respecto: "[T]ransculturation refers to an intercultural body associated with hybrid encounters and with a system that resists and contest the powers of domination" (288). Ella utiliza esta terminología para mostrar la manera en que el cuerpo femenino actúa en el escenario y lo adopta como espacio de encuentro poscolonial: "I propose to expand the idea of transculturation as it opens possibilities for understanding the intercultural body - the hybrid that can redefine notions of mestizaje itself" (288). La función de la transculturación es crear zonas de contacto que re-construyan, repersonifiquen, y vuelvan a conceptualizar los cuerpos que funcionan dentro 
de estos espacios. Es posible descolonizar el cuerpo en este encuentro y asignarle una nueva valorización. Los personajes que crea Cruz en su teatro son ejemplos de este tipo de transculturación, puesto que son un estereotipo re-apropiado al que se le asigna una re-valorización, lo que provoca que se enfrente a un discurso cultural hegemónico. Este enfrentamiento estético hace posible construir una nueva identidad cultural en escena, donde los cuerpos aparecen con una carga social (de género y etnia) pero que la autora está dispuesta a reformular.

Para lograr la creación de personajes que respondan a estas características, Cruz busca formar tipos femeninos que representen tanto lo positivo como lo negativo de la sociedad. Esta decisión artística de Cruz es de suma importancia, ya que reconoce la diversidad de lo femenino. Judith Butler, en su trabajo Gender Trouble, cuestiona la homogenización del sujeto "mujer":

If one "is" a woman, that is surely not all one is; the term fails to be exhaustive, not because a pregendered "person" transcends the specific paraphernalia of its gender, but because gender is not always constituted coherently or consistently in different historical contexts, and because gender intersects with racial, class, ethnic, sexual, and regional modalities of discursive identities. As a result, it becomes impossible to separate out "gender" from the political and cultural intersection in which it is invariably produced and maintained. (6) Por lo tanto, es imposible categorizar a la mujer bajo una subjetividad homogénea. Como señala Butler más adelante, es incluso impracticable el clasificar a la sociedad patriarcal bajo un mismo concepto de opresión.

Las múltiples realidades que enfrentan los personajes femeninos de Cruz representan el conflicto racial y social, aparte del sexual, en el que se existen. Ellas tienen que funcionar a partir de diferentes expectativas y no siempre caben dentro de la categoría tradicional "mujer latina". Alberto Sandoval observa cómo las imágenes de Hollywood y Broadway han perpetuado el estereotipo femenino latino: el de la "beautiful señorita", un "otro" deseado y sexualizado que ha sido creado para satisfacer a un público del mainstream. Este ser exótico se ha materializado en el colectivo patriarcal y anglosajón como una imagen ideal. Para poder revalorizar la representación femenina, ciertas autoras han tomado la responsabilidad de presentar el cuerpo de la mujer de manera diferente en escena. Como indica Sandoval:

U.S. Latina playwrights, via feminist critical practice and as an act of resistance, have responded to the iconic formation and fixation 
of the beautiful señorita. They have started to refract, disrupt, resist, and destabilize the male gaze and dominant cultural and patriarchal conventions of female dramatic representation. They have put into question the traditional and pleasure-granting ways of looking at the ethnic, racial, and sexual other... However, their feminist intervention and critical revision cannot be limited to only deconstructing stereotypes in the dominant Anglo-American cultural realm; they have also had to question and reevaluate stereotypical representations and gender roles of women in Latin American culture. Consequently, U.S. Latinas have had before them a double task: to deconstruct both Anglo and Latin American representation of gender and to create a space for self-representation and U.S. Latina experience. (152)

Efectivamente, el personaje femenino latino se encuentra ante dos realidades opresivas y patriarcales: el mainstream norteamericano y las sociedades latinoamericanas. Esto lleva a una revisión de la feminidad que se puede observar en los personajes de Cruz, pues el cuerpo femenino que aparece en escena puede estar deforme, o cubierto por pelaje, o con cortes en forma de flores. Así, la mujer se resiste a una percepción homogénea e impone imágenes conflictivas que permiten demostrar cierta complicación en su ser.

\section{El amor y la sexualidad}

La sexualidad en la obra de Cruz aparenta ser un motivo simple en los personajes, una manera de expresar un deseo o erotismo en algún momento específico. Sin embargo, se emplea de varias maneras por los personajes, quienes la utilizan con propósitos claros o la confunden en el momento de apropiarse de ella. Al hablar sobre la sexualidad en sus personajes femeninos, Cruz señala:

For my characters, sexuality is the only thing they feel particularly empowered with. It's their one tool through the world. They don't have money, they don't have good jobs. They don't necessarily have a good education, and, even if they do, it always breaks down into their giving up their bodies and exploring what it means to do so. How do you give it up? And if you give it up, do you do it gladly or is it painful? (López 211-12)

En otras palabras, la sexualidad es un arma. Y, al explorar su uso se pueden observar diferentes maneras de emplearla e, incluso, maneras en que se explota esa sexualidad. Cruz cuestiona las representaciones de la sexualidad femenina 
al preguntarse de qué manera maneja la mujer el erotismo que despierta en el hombre: ¿Qué simboliza el que una mujer se entregue?

En 1988 se pone en escena la obra más reconocida de Migdalia Cruz: Miriam's Flowers, que trata de la dinámica emocional entre madre e hija, marcada por el sufrimiento que ambas padecen desde la muerte del hermano menor, quien fue atropellado por un tren. La manera en que la joven protagonista, Miriam, resuelve su dolor es mediante su sexualidad y la autoflagelación. Miriam se corta la piel en forma de flores como un acto de martirio, dolor, purificación y, como consecuencia, de redención. Necesita ese dolor para sentirse viva, y compara su sufrimiento con el que sufrió Jesucristo y los santos mártires. Miriam, al hablarle a una estatua de la Pieta, confiesa: "I make little points that add up to a picture, a flower picture... and then I know I'm alive, 'cause it hurts so bad" (71). La relación entre madre e hija culmina con la muerte de Delfina, la madre, en una escena de dolor grotesco donde Miriam le corta la piel en forma de flores a la muerta para darle una dignidad final a su vida: "now they'll treat you like a saint" (83).

Miriam's Flower expone diferentes maneras de explorar la sexualidad. Para comenzar, está la contradicción entre sexo como recompensa o como castigo; binomio que se puede percibir en las diferentes maneras en que Delfina, la madre, y Miriam se acercan a su sexualidad. Hay que recordar que la acción que une y separa a la familia de esta obra es la muerte del hijo menor, y es a partir de esa tragedia que la sexualidad femenina se explora. Para Delfina, la madre, la sexualidad es parte de su condición femenina. Ella explora su sexualidad con su marido, Nando, y es posible notar cierta ambivalencia en la manera que percibe el paralelo amor/sexo en su relación con él. En las escenas donde aparecen actos sexuales, Delfina pasa de reacciones negativas a positivas, permitiéndose finalmente asociar el sexo con el amor. Así, éste se convierte en una recompensa, como pasa en la siguiente escena en la cual Nando le practica el sexo oral a Delfina:

$[H]$ is head is under her skirt. He speaks from there.

Delfina. You're disgusting.

Nando. Love can't be disgusting.

Delfina. Your's is. I always gotta wash after. Like five or six times. With soap...

Nando. (Holding the handkerchief to his nose.) Aaaahh! Smell that. It's us. Together. 
Delfina. ¡Ay! ¡Fo! ¡Pendejo! ¡Saca eso! Get out of here! I know what I smell like. Guava jelly. You told me that two hundred times now... You love me too much. (57)

La escena termina con ambos besándose, en una entrega mutua. Así, Delfina explora su sexualidad por medio del ser amado, pero es la tradición lo que la mantiene ambivalente hacia su propia sexualidad, puesto que no es "natural" que la mujer disfrute del sexo. Sin embargo, el amor le permite apropiarse de su cuerpo y ofrecerlo como recompensa al ser amado.

Por otra parte, Miriam entrega su cuerpo como escape de la realidad; para ella, el sexo es una manera de pagar la culpa que siente por la muerte de su hermano, o sea que el sexo es un castigo. Este representa un acto de violencia mediante el cual se evade del dolor y la culpa. La sexualidad desaforada transforma a Miriam en otra persona, lo cual le permite evadirse a si misma. Ella se convierte en un cuerpo sexualizado para pagar por sus culpas. Llega a un extremo de la sexualidad y entrega su cuerpo a cualquier extraño con tal de poder pagar por el sufrimiento en el que vive:

Every time one of them slipped his dick inside me, I felt that train running over Puli's face - crushing him, beating him down into the dirt between the rails. I imagined my body was Puli's.... He only got hurt once, but I hurt all the time for him. I take his hurt from his so he don't feel it no more. My pussy is his little brain being smooshed between metal. (64)

Esta es la única manera que Miriam encuentra para expresar su dolor. La sexualidad equivale a un castigo que más tarde compartirá con el acto de cortarse la piel. Utiliza su cuerpo como arma para conseguir las navajas que necesita, puesto que se acuesta con Enrique, el dueño de una tiendita, para que se las regale. Enrique es bastante mayor que ella, pero está dispuesto a intercambiar sexo por navajas. De esta manera, ella adopta la violencia sexual como parte de sí misma y escoge esta profanación para expresar su sufrimiento.

Miriam es un sujeto deseado por múltiples hombres, y ella, a su vez, actúa como sujeto deseante ante la religión, espacio en el que encuentra otro escape. Esta combinación sirve para demostrar la trasgresión por la que está pasando en torno a la sexualidad que practica. A la vez que entrega su cuerpo a cualquiera, se corta la piel para sentirse más cerca de la santidad que anhela. Es interesante observar sexualidad y religión desde la perspectiva que ofrece Georges Bataille, al comentar como ambas llevan a una soledad comparable a la muerte: 
El paso del erotismo a la santidad tiene un sentido profundo. Es el paso de lo que es maldito y rechazado a lo que es fausto y bendito. Por un lado, el erotismo es la culpa solitaria, lo que sólo salva oponiéndonos a todos los demás, lo que sólo nos salva en la euforia de una ilusión, ya que, en definitiva, lo que en el erotismo nos ha llevado al grado extremo de la intensidad, nos condena al mismo tiempo a la maldición de la soledad. Por otra parte, la santidad nos aleja de la soledad, pero con la condición de aceptar esta paradoja felix culpa! - cuyo exceso mismo nos redime... El acuerdo con sus semejantes sólo vuelve a encontrarlo el cristiano con la condición de no gozar más de aquello que lo libera, que sin embargo no es nunca sino la trasgresión, la violación de las prohibiciones sobre las que descansa la civilización. (268)

Si se observan las acciones de Miriam desde esta perspectiva, se puede ver cómo no existe salida a la penitencia que se impone. La sexualidad es una trasgresión que utiliza para castigarse a sí misma, y la religión es un escape que no le permite redimirse al no poder escapar su culpa. Ella está sola y termina sola, ya que la obra acaba con la muerte de Delfina y se debe recordar que Nando era su padrastro, por lo que ahora no tiene ni madre, ni padre, ni hermano. Por esta misma razón, la estética religiosa que aparece en la obra es sumamente necesaria. La santidad que busca es lo que la empuja a sentir una culpabilidad que la mantiene en el deseo por destruirse a sí misma. Sin embargo, esa destrucción que imparte sobre su cuerpo es la forma en que se recuerda a sí misma que no ha muerto a pesar de la soledad en la que vive. Su cuerpo está totalmente sexualizado y, por lo tanto, está destruido, ya que ella se ha apropiado de la sexualidad al utilizar el sexo como arma de purgación.

La sexualidad en la obra de Cruz adquiere una multiplicidad de usos. Se puede ligar con la atracción y el exotismo, pero también, la sexualidad exotizada se asocia con el deseo lesbiano, como sucede en Fur. En esta obra, estrenada en 1991, Citrona, quien es casi un animal debido a su condición de mujer hirsuta enjaulada, es la que siente el deseo homoerótico. Esta obra narra un triángulo amoroso entre Citrona, que es propiedad de Michael, quien dice amarla al mismo tiempo que la mantiene dentro de una jaula, y Nena. Citrona dice amar a Nena, cazadora de animales, quien está enamorada de Michael. La relación de amor y odio entre estos tres personajes constituye a unos y destruye a otros, mientras revela los temores que todos sufrimos y escondemos. La combinación de homoerotismo y monstruo hacen de Citrona algo tan exótico ante los otros personajes que les es difícil apreciarla o entenderla. Sin embargo, 
lo exótico no adquiere una connotación negativa, porque ella es la más humana de estos personajes, la más fuerte y la más honesta. Esta representacion del deseo homoerótico sirve para enseñar otro extremo sexual, puesto que expone también a la lesbiana que no logra aceptarse a sí misma y es construida negativamente por otros. Por lo tanto, el homoerotismo equivale a una manera de explorar la sexualidad femenina desde ángulos "prohibidos" por la sociedad hegemónica. La sexualidad se mantiene, entonces, como una trasgresión que no tiene porqué ser necesariamente vista desde una connotación negativa. Sandoval Sánchez expresa claramente la trasgresión que provoca el deseo homoerótico, ya que cuestiona el orden patriarcal y hegemónico:

Focusing on lesbian desire...calls into question internalized heterosexisms and homophobia in an effort to break the taboo of lesbian sexuality within U.S. Latina communities. By exposing lesbian sexuality, the protagonists disrupt patriarchal discourses and horizons of expectations that employ femininity to secure and perpetuate the male power relations that Teresa de Lauretis has described in her Sexual Indifference and Lesbian Representation: "The construction and appropriation of femininity in Western erotic ethos has also had the effect of securing the heterosexual social contract by which all sexualities, all bodies, and all 'others' are bonded to an ideal/ideological hierarchy of males". (162)

El homoerotismo revierte la sexualidad femenina impuesta por el mainstream que, como se ha dicho, hace objeto a la mujer como sujeto deseado. En el teatro de Cruz, la sexualidad es re-apropiada por la mujer de diferentes formas, y estas no son siempre necesariamente positivas, pues se busca presentar la complejidad del cuerpo femenino sexualizado, ya sea como sujeto deseado o sujeto deseante.

Así como la sexualidad forma parte del imaginario que se explora en la obra teatral de Cruz, el amor surge también como una forma de entender a la mujer y la forma en que puede distorsionar este sentimiento. El amor aparece en todas sus formas, desde pasión hasta obsesión, y afecta a los personajes de diferentes maneras. Al igual que la sexualidad les sirve a los personajes para escapar de la realidad, el amor tiene una función similar. Los personajes enamorados son incapaces de operar dentro de la realidad, y se esconden en un mundo lleno de distorsiones. Un buen ejemplo de esto se encuentra en Fur, donde los personajes se recluyen en un sótano que poco a poco se va llenando de arena y pieles de animales. Es en este espacio donde se van desarrollando sus historias de amor y pasión, ajenas a la realidad de 
afuera que está representada por una parte del escenario llamado "no-space". No está claro si ese espacio afecta a los personajes de alguna manera, ya que estos son incapaces de funcionar en la realidad. Para ellos el amor se convierte en una adicción que los afecta hasta el punto que lo único que existe en su mente es esa distorsión del amor.

En Fur, el triángulo amoroso tradicional formado por relaciones heteronormativas, se invierte. En la situación tradicional la experiencia femenina está vinculada a la del hombre, que es internalizada por la mujer, puesto que la fantasía está guiada por el ser masculino que lucha por el objeto deseado. Es distinto cuando la relación consiste en mujer-hombre-mujer, y, sobre todo, si el personaje principal, Citrona, expresa un deseo homoerótico hacia la otra mujer. En el caso de esta obra, el primer problema es que el amor se equipara con la muerte, puesto que la solución que Citrona encuentra para el amor no correspondido es esta. Parecería que es la única forma de poseer al ser amado. La relación entre Citrona y Nena se complica con la búsqueda por una identidad, pues el deseo que ésta siente por Nena es también un deseo por convertirse en esa persona. Bataille explica esta necesidad de unión al expresar la relación que existe entre amor y muerte:

La posesión del ser amado no significa la muerte, antes al contrario; pero la muerte se encuentra en la búsqueda de esa posesión. Si el amante no puede poseer al ser amado, a veces piensa matarlo; con frecuencia preferiría matarlo a perderlo. En otros casos desea su propia muerte. Lo que está en juego en esa furia es el sentimiento de una posible continuidad vislumbrada en el ser amado. Le parece al amante que sólo el ser amado - cosa que proviene de correspondencias difíciles de definir, donde a la posibilidad de unión sensual hay que añadir la de unión de los corazones - puede, en este mundo, realizar lo que nuestros límites prohíben: la plena confusión de dos seres, la continuidad de dos seres discontinuos. (25)

Así, amor y sufrimiento están ligados, pues en la búsqueda de uno se encuentra el otro. Citrona se da cuenta de que no es posible encontrar amor con Nena, por lo que la mata. A partir de estas acciones, ella se compara con el monstruo Frankenstein y explica como un monstruo solamente busca el amor: "I wanted love and I used to dream about that.... [People] always expect us to kill the things we love. And there's some truth to that too. Because when I love someone I know she'll never love me back and so I want to kill her" (90). Esta conexión entre el amor y el deseo por la belleza aparece en Citrona a partir de la relación con su madre, quien la odiaba por su físico. El resultado 
es que desea todo aquello que es bello, delicado y de color rosado, todo lo que no identifica consigo misma. La única manera de obtener esto es por medio del deseo lésbico; un deseo que se traduce en el anhelo por poseer lo estereotípicamente femenino. El físico de Citrona es opuesto a lo que tradicionalmente se desea en una mujer, y esto es lo que la lleva a cuestionar su feminidad y la convierte en un "monstruo".

El personaje de Citrona confunde el amor con el acto de poseer, puesto que finalmente lo único que quiere es que Nena se someta. De esta manera, Citrona adopta un rol "masculino", o al menos lo que ella supone que éste debe ser. Al comportarse de esta manera, se convierte en la destructora y adquiere el control sobre todos al final de la obra. A pesar de tener este control, Citrona se detesta a sí misma, lo que nos lleva a cuestionar por qué no se autodestruye al ser ella la fuente de tanto odio. Una posible respuesta es que para Citrona la muerte no es un castigo, sino una manera de conseguir liberación. Y, esa libertad no es posible para si misma porque no se siente digna, por lo que le ofrece esa liberación a los seres que ama. La relación entre Citrona y Nena termina en la muerte, y la relación entre Citrona y Michael termina con un grito. Esto nos lleva a pensar que la muerte es obligada para Nena, que es el ser amado. Sin embargo, para Michael hay un final no definido, puesto que el grito no es explicado y puede interpretarse como dolor o placer.

Para Citrona, el sexo con Nena es una recompensa; es algo puro y bello, pero con Michael es un castigo, algo que equipara a la muerte. En el caso de Nena es todo lo contrario, ella siente que una simple caricia por parte de Citrona la mataría del asco. Para Nena, la sexualidad de Michael es la recompensa, ya que éste es el objeto de su obsesión y alguien que ella percibe como puro. De ahí que esté siempre vestido de blanco. Para Michael, las relaciones sexuales con Nena son una posibilidad, pero no parte de su deseo erótico. Él desea a Citrona, quiere dominarla y la considera una posesión; por eso la compró. Todos estos personajes equivalen el amor a la posesión del ser "amado". El amor se convierte en una enfermedad que afecta y distorsiona la realidad, que los va hundiendo (en este caso, con el pasar de la obra, el escenario se va cubriendo de arena, la cual simbólicamente va inundando el sótano en donde ocurre la acción).

El amor en sí funciona como una prisión, y esto se puede observar literalmente en las acciones en escena. Primero, Michael enjaula a Citrona y le promete la libertad solamente si acepta casarse con él. Citrona, por otro lado, enjaula a Nena con ella para así poder expresarle su amor. Nena, por su parte, escoge encerrarse en la casa de Michael, espacio que espera compartir 
con él. Esto hace que cada vez que se encuentra con él pierda la memoria de la realidad y de su identidad, ya que Michael actúa como una presencia opresora que le niega todo pasado identitario a Nena y la libertad a Citrona. Nena ama a Michael porque éste le ofrece una memoria construida, o lo que ella percibe como una memoria en tanto a las enseñanzas que Michael le ofrece. Es importante que Nena no tenga recuerdos que la identifiquen ante Michael, pues, como señalan Gilles Deleuze y Félix Guattari, “el recuerdo bloquea al deseo, lo calca, lo hace regresar a los estratos, lo separa de todas sus conexiones" (12). Así, el deseo impone la sumisión, juzga y condena mientras que el recuerdo desplaza al deseo y lo separa de sus conexiones. De esta manera, existe una división entre bloque y recuerdo, que en la obra aparecen como lo que impone Michael y olvida Nena. El bloque "levanta al deseo en vez de hundirlo, lo desplaza en el tiempo, lo desterritorializa, hace que proliferen sus conexiones, lo hace pasar a otras intensidades" (Deleuze y Guattari 13). Es necesario que Nena no tenga recuerdos para así continuar su amor/deseo por él y para permanecer como su esclava.

Nena no tiene memoria propia porque la subjetividad masculina la constituye como sujeto femenino. Ella representa una mujer aceptable en tanto a los estándares patriarcales: no tiene identidad racial, es sumisa y servicial, a la misma vez que es atractiva y capaz. Citrona, al contrario, es la mujer "natural" y marginada, por lo que permanece enjaulada. De esta manera, Nena es una construcción falsa de lo femenino. Sin embargo, ambas representaciones son prisioneras del amor. No hay posibilidad de que funcione el amor en ninguno de los tres casos, puesto que las distorsiones sociales en las que los personajes existen provocan que transformen el amor en obsesión y posesión.

El teatro de Cruz crea imágenes innovadoras de la identidad femenina. Estas construcciones de lo femenino se desarrollan en espacios escénicos específicos por medio de un lenguaje concreto. Pero, Cruz no construye un mismo patrón de identidad femenina. Dentro de sus obras existen ciertos estereotipos que se exploran y se re-construyen. Personajes como la madre, la hija o la lesbiana aparecen en estos escenarios con el fin de transformarse, formando así diferentes patrones femeninos. Judith Butler, como ya se señaló, indica la importancia de recalcar que no existe un sujeto único llamado "mujer", sino que hay muchas variantes influenciadas por raza, cultura y economía, entre otros elementos. No hay una feminidad universal:

Universalistic claims are based on a common or shared epistemological standpoint, understood as the articulated consciousness or shared 
structures of oppression or in the ostensibly transcultural structures of femininity, maternity, sexuality, and/or écriture feminine....[T]he insistence upon the coherence and unity of the category of women has effectively refused the multiplicity of cultural, social, and political intersection in which the concrete array of "women" are constructed. (19-20)

La categoría de "mujer" es una categoría incompleta, que no puede utilizarse para señalar una identidad basada en género, dado que el concepto de género en sí mismo es bastante complejo. Butler se pregunta muy acertadamente:

To what extent do regulatory practices of gender formation and division constitute 'identity,' the internal coherent of the subject, indeed, the self identical status of the person? To what extent is identity a normative ideal rather than a descriptive feature of experience? (23)

Estas construcciones se pueden ver como normas impuestas socialmente que afectan el entendimiento de un "yo". Es por esto que no se puede percibir a las mujeres del teatro de Cruz bajo el mismo concepto de feminidad; su construcción representa diferentes conceptos que no siempre caben dentro del sujeto llamado socialmente "mujer". Estos personajes rompen e imponen patrones, ya que los estereotipos que se retoman no son regulados "apropiadamente", y así la hija puede deformarse y transformar su sexualidad como en Miriam's Flowers y la lesbiana puede ser elevada a un plano de poder como en Fur, entre otros modelos. Como señala Butler, la imposición de ciertos patrones de identidad es producto de prácticas normalizadoras que pretenden imponer una conformidad social (23-24). El concepto de identidad sexual no tiene por que caber dentro del plano que se le pretende imponer; es posible que se construyan y formen identidades subversivas que abran esos planos impuestos socialmente. En el caso del teatro de Cruz, se puede observar cómo el concepto de identidad femenina no es único ni pretende serlo. Las mujeres de estas obras pueden no caber dentro de la idea de feminidad e, incluso, es posible que la masculinidad entre dentro de la construcción de estas identidades, como se puede observar en personajes como Citrona en Fur.

\section{Reformulaciones de la identidad en el teatro de Migdalia Cruz}

Como hemos visto hasta ahora, el teatro de Migdalia Cruz presenta una serie de reconfiguraciones en torno a tematicas que transforman la manera en la cual se percibe al sujeto "latino" en el escenario. La forma más apropiada para estudiar las expresiones artísticas latinas, según la representan 
autores como Migdalia Cruz, me parece, es desde la perspectiva que ofrecen los teóricos Gilles Deleuze y Félix Guattari. Su concepto de literatura menor sirve como acercamiento, puesto que se pueden entender las expresiones de esta cultura como una literatura atrapada entre conciencias nacionales opresoras. Dicen Deleuze y Guattari:

Una literatura menor no es la literatura de un idioma menor, sino la literatura que una minoría hace dentro de una lengua mayor.... Su primera característica es que, en ese caso, el idioma se ve afectado por un fuerte coeficiente de desterritorialización. (29)

$\mathrm{Su}$ propuesta se relaciona con la imposibilidad de la escritura. Deleuze y Guattari utilizan la idea de imposibilidad de escritura en relación a la desterritorialización que sufre un idioma en el caso de una literatura menor. Utilizan a Kafka por esta misma razón:

La imposibilidad de escribir en otro idioma que no sea el alemán es para los judíos de Praga el sentimiento de una distancia irreductible con la territorialidad primitiva checa. Y la imposibilidad de escribir en alemán constituye la desterritorialización de la población alemana misma, minoría opresora que habla un idioma ajeno a las masas, como un lenguaje de papel o artificial.... En fin, el alemán de Praga es una lengua desterritorializada, adecuada para extraños usos menores. (29) El caso de los latinos en Estados Unidos es similar, puesto que escriben en un idioma desterritorializado debido a las mismas imposibilidades de escritura. Para estos no existe la posibilidad de escribir en otro idioma que no sea inglés. Sin embargo, escribir en ese idioma hegemónico también es una imposibilidad. Al decir esto me refiero a la imposibilidad del latino para escribir en un idioma aceptado por la sociedad hegemónica. Esta misma obliga a escribir en el idioma normativo, en este caso el inglés, y por lo tanto este es el idioma que supuestamente rige la escritura de este país. Estas son posibilidades ideológicas, ya que el latino toma un posicionamiento ideológico respecto de la elección del idioma en el cual va a escribir, re-apropiándose del idioma y desterritorializándolo para expresar los vínculos que constituyen su situación social. La solución que se encuentra en muchos casos es el uso del "codeswitching", o el cambio de código lingüístico, técnica que desterritorializa aún más el uso de cualquier idioma. Ante la imposibilidad de la escritura, el latino se lanza a escribir en los dos idiomas que lo constituyen, un uso de inglés y español que no es "apropiado". Desde esta perspectiva, me pregunto si se puede ver a la literatura latina en Estados Unidos como una literatura menor atrapada entre dos conciencias nacionales opresoras: Estados Unidos/ 
Europa y Latinoamérica. La imposibilidad ante la escritura debido a ese poder opresor hace consciente al latino de la misma en un idioma que no sea inglés o español (o ambos), y la imposibilidad de escritura en estos, ya que ambos les son negados al no "pertenecer" a ninguna de estas dos culturas.

En el teatro de Migdalia Cruz es posible observar cómo el uso del lenguaje se utiliza para presentar un mundo desterritorializado. Deleuze y Guattari identifican el uso del lenguaje por la literatura menor como una máquina de expresión colectiva, que se relaciona con la desterritorialización de la expresión. Ellos se preguntan:

¿Cuántos viven hoy en una lengua que no es la suya? ¿Cuánta gente ya no sabe ni siquiera su lengua o todavía no la conoce y conoce mal la lengua mayor que está obligada a usar? Problema de los inmigrantes y sobre todo de sus hijos. Problema de las minorías. Problema de una literatura menor pero también para todos nosotros: ¿cómo arrancar de nuestra propia lengua una literatura menor, capaz de minar el lenguaje y de hacerlo huir por una línea revolucionaria sobria? (33) El lenguaje es importante para la literatura menor porque es la característica que se usa para alienarla. Esto mismo es lo que ocurre con el latino y se puede ver en el teatro de Cruz. Las obras adoptan el lenguaje de este sector cultural, con sus características particulares. No se intenta imponer el lenguaje opresor, pero se utiliza el lenguaje propio del latino. Por ejemplo, en Fur hay una escena que está escrita completamente en español y transcurre en un mundo de fantasía. Los personajes pueden expresar sus emociones en este idioma y fuera de la realidad; mientras la realidad les impone el inglés como lengua que, por otro lado, no les permite expresar lo que verdaderamente sienten. De la misma manera, el inglés "formal" es otro espacio inalcanzable, ya que está fuera de los parámetros que habitan los personajes principales a los que las vías institucionales de educación formal no les son asequibles. La imposibilidad de la palabra es lo que caracteriza a estos personajes.

Otra característica de la literatura menor según Deleuze y Guattari es el aspecto político que se mezcla en la obra. Para ellos todo problema individual se conecta al problema político, y todo se hace político dentro de esta literatura. El problema individual que en las grandes literaturas coloca lo social y político de trasfondo, la literatura menor lo emplea de diferente manera:

El espacio reducido hace que cada problema individual se conecte de inmediato con la política. El problema individual se vuelve entonces tanto más necesario, indispensable, agrandado en el microscopio, 
cuanto que es un problema muy distinto en el que se remueve en su interior. (29)

Esto se puede ver en la obra de Cruz, donde la relación entre los personajes abarca el vínculo de una cultura frente a un problema político específico. Al presentar personajes marginados por su manera de funcionar frente a una sociedad opresora, su teatro hace de todo tema algo que va más allá de una simple historia representada. Es cierto que Cruz no presenta el problema político de una manera obvia, como lo hizo, por ejemplo, el Teatro Campesino. A pesar de desarrollarse en un ámbito más íntimo, el nivel político no escapa de su obra, dado que los personajes presentan los problemas en un espacio de relaciones familiares o amorosas.

Por último, de acuerdo a Deleuze y Guattari, la tercera característica de la literatura menor es que todo adquiere un valor colectivo. De esta manera, cada esfuerzo literario se aprecia adentro de un conjunto:

Lo que el escritor dice totalmente sólo se vuelve una acción colectiva, y lo que dice o hace es necesariamente político, incluso si los otros no están de acuerdo. El campo político ha contaminado cualquier enunciado. [...] De esta manera, la máquina literaria revela a una futura máquina revolucionaria, no por razones ideológicas, sino porque sólo ella está determinada para llenar las condiciones de una enunciación colectiva, condiciones de las que carece el medio ambiente en todos los demás aspectos: la literatura es cosa del pueblo. (30)

La literatura menor se produce en medio de otras literaturas ya establecidas o mayores. Es decir, tiene que luchar por revelarse y crear una voz a pesar de existir entre otras voces que intentan oprimirla. Este hecho hace que cada voz menor pase a representar un colectivo que opera dentro de esa minoría. Por eso, a Migdalia Cruz se le aprecia dentro de la literatura Neorriqueña y, más allá, como autora latina. Pero, el colectivo latino en Estados Unidos forma parte también de una enunciación menor dentro del imaginario latinoamericano y estadounidense. El hecho de que exista como parte de una enunciación híbrida hace de la voz latina una voz transformadora. La producción de Migdalia Cruz forma parte de un grupo cultural, y su obra presenta la lucha política y social que enfrenta ese colectivo.

Ahora, me parece interesante observar cómo es que funciona una literatura menor que nace en medio de dos literaturas mayores. La influencia de los grandes maestros latinoamericanos influye tanto como la cultura hegemónica estadounidense donde producen estos autores. Sin embargo, 
muchos de estos tienden a identificarse con Latinoamérica más que con Estados Unidos. Esta división es tan compleja como la división que existe dentro de Latinoamérica al intentar representarse de manera homogénea bajo un sólo nombre y una sóla definición. Después de todo, como señala Diana Taylor, "sameness cannot be assumed between those who share certain positions of proximity...the monolithic vision of an undifferentiated Latin America can only be maintained by those outside it" (6-9). Es imposible clasificar la literatura latina en los Estados Unidos bajo una sóla categoría, e intentar asociarla con una misma cultura. La obra de estos artistas se puede incluir bajo el imaginario de la producción latinoamericana como una continuación que forma parte de una historia de emigrantes e exiliados. Los problemas que exploran estos artistas afuera de Latinoamérica forman parte de una narración transfronteriza, que incluye imágenes de los dos lados. Esta idea de Latin/o América que explora Taylor es válida en el sentido de que intenta romper con divisiones con el fin de explorar una continuación de tradiciones y producciones que van más allá de un discurso de fronteras.

La idea de literatura menor sirve dentro de este discurso para caracterizar la producción literaria que se produce en esta transfrontera. Es difícil encasillar la literatura latina, puesto ¿qué pasa cuando se produce en español en países latinoamericanos? ¿Es entonces considerada como literatura extranjera? Por ejemplo, algunas obras de Migdalia Cruz han sido producidas en español en teatros de México y Puerto Rico. A pesar de cualquier distancia que quiera guardar un público latinoamericano con una autora que no habla español, la obra en sí forma parte de su imaginario, y no la consideran como algo extraño. Entonces, ¿es latinoamericana la obra de Cruz en este contexto? Un lenguaje no va a categorizar una obra, si acaso puede desterritorializarla en la producción, como señalaron Deleuze y Guattari. Cuando se traduce una obra de teatro de Cruz y se produce en México, el público la acepta como parte de su imaginario colectivo, por lo que los personajes marginados de Cruz forman parte de la colectividad marginal latinoamericana de la misma forma que son identificables con la colectividad híbrida latina. Así, este teatro forma parte de una literatura menor que enlaza a diferentes colectividades, ambas al margen de una sociedad opresora que impone una voz universal: Europa/Estados Unidos. Las expresiones teatrales que crean diferentes autores latin/o americanos forman parte de un discurso popular que puede fusionar a ambos lados marginados de la frontera.

El hecho de que se estudie lo latino como una colectividad que fusiona imaginarios no equivale necesariamente a homogeneizar una 
cultura. Me parece que equiparar esta literatura con una literatura menor provoca una distinción de voces. Es posible distinguir una variedad dentro de una colectividad y, por lo tanto, ver el teatro de Migdalia Cruz como la experiencia de una literatura menor. Así, es posible descubrir su teatro como una variante dentro de una colectividad. Si la producción latina forma parte de una literatura menor, entonces, su expresión presenta una variedad de voces. La voz de Migdalia Cruz es una de las muchas voces que no caben dentro de la literatura mayor, pues ésta intenta homogeneizar la producción dentro de una categoría de "literatura universal" que excluye la variedad y opaca las voces de la diferencia.

California State University, Fresno

\section{Bibliografía}

Arrizón, Alicia. "Transculturation and Gender in US Latina Performance." Theatre Research International 24.3 (1999): 288-92.

. Latina Performance: Traversing the Stage. Bloomington: Indiana UP, 1999

Bataille, Georges. El erotismo. Barcelona: Tusquets Editores, 2002.

Butler, Judith. Gender Trouble: Feminism and the Subversion of Identity. New York: Routledge, 1990.

Cruz, Migdalia. Miriam's Flowers. Shattering the Myth: Plays by Hispanic-American Women. Ed. Denise Chávez. Houston: Arte Público Press, 1992.

. Fur. Out of the Fringe: Contemporary Latina/Latino Theatre and Performance. Eds. Caridad Svich y María Teresa Marrero. New York: Theatre Communications Group, 2000.

De Beauvoir, Simone. The Second Sex. New York: Everyman's Library, 1993.

Deleuze, Gilles and Félix Guattari. Kafka. Por una literatura menor. México: Ediciones Era, 1978.

Huerta, Jorge. "Negotiating Borders in Three Latino Plays." Of Borders and Thresholds: Theatre History, Practice and Theory. Ed. Michal Kobialka. Minneapolis: U of Minnesota P, 1999.

Chicano Drama: Performance, Society and Myth. Cambridge: Cambridge UP, 2000.

López, Tiffany Ana. "Violent Inscriptions: Writing the Body and Making Community in Four Plays by Migdalia Cruz." Theatre Journal 52.1 (2000): 51-66.

Sandoval-Sánchez, Alberto. José, Can You See? Latinos on and Off Broadway. Madison: U of Wisconsin P, 1999. 
Sandoval-Sánchez, Alberto y Nancy Saporta Sternbach. Stages of Life: Transcultural Performance and Identity in U.S. Latina Theater. Tucson: U of Arizona P, 2001.

. Puro Teatro: A Latina Anthology. Tucson: U of Arizona P, 2000.

Taylor, Diana y Juan Villegas. Negotiating Performance: Gender, Sexuality, and Theatricality in Latin/o America. Durham: Duke UP, 1994. 